\title{
La teta asustada: de Theidon a Llosa
}

\author{
La teta asustada: From Theidon to Llosa
}

\author{
Giovanna Pollarolo \\ Pontificia Universidad Católica de Perú
}

RESUMEN: Cuando se difundió el filme La teta asustada (2009), dirigido por Claudia Llosa, quienes habían leído Entre prójimos. El conflicto interno y la política de la reconciliación en el Perú (2004) - investigación realizada por la antropóloga médica Kimberly Theidon en siete comunidades ayacuchanas entre 1995 y 2000 - se preguntaron por la relación de dicho estudio con la película de Llosa pues el término "teta asustada" es una traducción que hace Theidon de la expresión quechua Mancharisqa Nuñu que hace referencia a la enfermedad que trasmitieron las madres a sus bebés durante la época del conflicto armado en el Perú.

Pese a que en el filme no se cita el libro ni se lo menciona como una fuente, en más de una entrevista Llosa declaró que la lectura de Entre prójimos fue el punto de partida para su película. Por otro lado, Theidon se enteró de "La teta asustada" cuando la película ganó el "Oso de Oro" en el Festival de Berlín (2010). En el presente trabajo me interesa indagar, desde una perspectiva intertextual, en el diálogo que se establece entre ambos textos y la manera como Llosa "lee", ficcionaliza, se acerca y también se distancia de la investigación realizada por la antropóloga.

ABSTRACT: When the film La teta asustada (2009), directed by Claudia Llosa, was released, who had read Entre prójimos. The internal conflict and the politics of reconciliation in Peru (2004) - research carried out by the medical anthropologist Kimberly Theidon in seven Ayacucho communities between 1995 and 2000- asked themselves about the relationship of this study with the Llosa film, as the term "scared tit" is a translation by Theidon of the Quechua expression Mancharisqa Nuñu that refers to the disease transmitted by mothers to their babies during the time of the armed conflict in Peru.

Although in the film the book is not quoted or mentioned as a source, in more than one interview Llosa declared that the reading of Entre prójimos was the starting point for her film. On the other hand, Theidon found out about "La teta asustada" when the film won the "Golden Bear", at the Berlin Festival (2010). In the present work I am interested in search, from an intertextual perspective, the dialogue established between both texts and the way Llosa "reads", fictionalizes, she approaches and also distances herself from the research carried out by the anthropologist.

PALABRAS CLAVE: adaptación, intertextualidad, ficcionalización

KEYWORDS: adaptation, intertextuality, fictionalization

RECIBIDO: 15 de febrero de 2018 • ACEPTADO: 30 de mayo de 2018 



\section{Giovanna Pollarolo}

Pontificia Universidad Católica de Perú

\section{La teta asustada: de Theidon a Llosa}

En Entre prójimos. El conflicto interno y la política de la reconciliación en el Perú (2004), la antropóloga médica Kimberly Theidon da cuenta de los resultados del proyecto de investigación "Reconciliando el pasado, construyendo el presente: violencia política y salud mental en Ayacucho". A lo largo de 31 meses, entre 1995 y 2000, Theidon entrevistó a los pobladores de siete comunidades y distritos ubicados en Ayacucho, región que fue escenario principal del conflicto armado iniciado en 1980 y que se prolongaría hasta 1992, año en el que fue capturado Abimael Guzmán, líder del Partido Comunista Sendero Luminoso. A partir de la necesidad de "historizar la violencia de las décadas de 1980 y 1990" (21), el objetivo del estudio era conocer el impacto de la guerra en las comunidades estudiadas, así como las estrategias psicológicas y sociales con las que los sobrevivientes del conflicto enfrentaron el proceso de reconstrucción y reconciliación. Theidon buscó identificar los traumas posconflictos que se manifiestan en "enfermedades del alma y del cuerpo" así referidas por los pobladores entrevistados,

Según el estudio de Theidon, los pobladores perciben que los males que padecen son exteriores: “'agarran a la persona' y 'entran en ella'; tal es el caso de la trasmisión al bebé del sufrimiento y del susto de la madre, sea esta trasmisión en el útero o por medio de la sangre y de la leche" (77). Muchos testimonios de las campesinas quechuahablantes le permitieron a Theidon acuñar el término "teta asustada" para referirse a este mal, que en quechua se nombra como Mancharisqa Nuñu. 
“Nuñu puede ser 'leche' y 'teta': la mujer sufrió el susto, 'la rabia, el sufrimiento y la tristeza"” (50), y con su leche y con su sangre se lo trasmite al bebé. Así describe Theidon en Entre prójimos, el mal de "la teta asustada".

Años después de la publicación de Entre prójimos, la directora de cine Claudia Llosa escribió el guion de la película que luego filmaría bajo el título de La teta asustada, filme que ganó el "Oso de Oro", en el festival de Cine de Berlín en 2010. Aunque en la película no se cita el trabajo de Theidon, en el presente estudio me interesa mostrar la relación intertextual evidente y explícita entre ambos textos. Para ello, en primer lugar reseñaré brevemente el trabajo de Theidon; y, luego, discutiré si es posible postular, y en qué términos, que estamos ante un caso de "adaptación".

\section{La investigación de Theidon}

Theidon enfatiza que durante el conflicto armado los campesinos no estuvieron, como muchos investigadores lo señalaron, entre "dos fuegos": el de Sendero Luminoso y el de las Fuerzas Armadas, sino que conformaron un "tercer fuego"; es decir, tomaron partido por uno u otro bando y participaron activamente en el conflicto. De allí que, tal como lo refieren muchos testimonios de los comuneros, durante el Sasachakuy tiempo (los años difíciles), se mataron entre conocidos, vecinos y amigos: "entre prójimos" (21). ${ }^{1}$ La naturaleza fratricida del conflicto implica que después de 20 años de violencia política, "en cualquier comunidad viven ex senderistas, simpatizantes, viudas, licenciados, huérfanos" (20), y la pregunta es: con qué estrategias psicológicas y sociales enfrentan el proceso de reconstrucción y reconciliación que permitirán

"Los senderistas atacaron por la noche. Estábamos durmiendo. El olor del humo nos despertó; los techos, todo en llamas. Después los gritos, agarramos a nuestros hijos y corrimos hacia el río. Era oscuro, pero estaban encapuchados. Si habían quitado sus máscaras, los hubiéramos reconocido. Eran nuestros vecinos. Dios Tayta, hemos visto lo que nuestros vecinos pueden hacer". Este testimonio recogido por Theidon (25) y que cita como epígrafe del capítulo 1 "Sasachakuy tiempo: los años difíciles" da cuenta del conflicto armado y la participación de las comunidades. 
convivir a "víctimas, perpetradores y aquel segmento significativo de la población que borra la dicotomía anterior" (20). Y es que, como bien señala Theidon, en las guerras internas el enemigo es un "“enemigo íntimo' - un vecino, una nuera, un padrino o la comunidad de enfrente" (22), de manera que, los procesos de reconciliación, administración de justicia y la recuperación de la salud mental, están vinculados estrechamente y no pueden reducirse a tratamientos individuales enfocados en lo psicológico, tal como lo propone el diagnóstico de estrés postraumático (PTSD, por sus siglas en inglés).

Asimismo, el tratamiento de los traumas en una sociedad posconflicto no puede separar lo somático de lo psicológico y de lo cultural, especialmente en culturas como las quechuahablantes en las que "esta división entre mente, cuerpo y alma está ausente de la concepción del ser humano" (42). Tampoco se debe soslayar la situación de pobreza e injusticia social, el menosprecio étnico, la indiferencia de gran parte de la sociedad peruana a la población campesina. Como se sabe, de acuerdo con el Informe Final de la Comisión de la Verdad y Reconciliación (CVR), 79\% de las víctimas fatales del conflicto armado vivía en zonas rurales; y $75 \%$ tenía el quechua, u otras lenguas nativas, como idioma materno; es decir, como advierte Theidon "una 'epidemiología' de la violencia política en el Perú demuestra que la muerte y la desaparición fueron distribuidas según geografía, clase y etnicidad" (19).

En suma, la investigación de Theidon tiene como eje central y punto de partida la hipótesis según la cual "la patología se halla en las formas estructurales y políticas de la violencia, y en un contexto de terror. Cuando el cuerpo individual comunica la angustia, podemos escuchar en él el malestar social" (50), malestar que se constata a lo largo de los prolongados diálogos sostenidos durante el periodo del trabajo de campo, "con 403 personas entre hombres, mujeres, niños y niñas" (37) que vivieron la violencia política y sus consecuencias y deseaban compartir sus recuerdos y males del presente.

Así, escuchando las preocupaciones, enfermedades, problemas y angustias de los entrevistados, iban apareciendo, señala Theidon, "trastornos sociales, dioses enrabiados, hechicería, confusión espiritual y moral" (44) cuya curación solo es posible si se atiende el contexto cultural y social; si se presta atención a "los vínculos estrechos entre la 
psicología social, la pobreza y las relaciones sociales tensas en muchos de estos pueblos" (58).

Tras la experiencia de escucha y diálogo, Theidon concluye que no es posible recuperar, sanar, individuos "sin reparar el entorno social en el cual viven": si una mujer sigue viviendo frente a su violador, o un padre ve al asesino de su hijo en la feria cada semana "¿dónde ubicamos el "trastorno? ¿Hay un trastorno mental o un trastorno de las relaciones sociales producto de la injusticia y de la impunidad?" (43), se pregunta. Es obvio, señala, que el mal es social.

Dicho esto, me interesa ahora centrarme en algunos de los males referidos en las entrevistas, aquellos que le permitieron a Theidon corroborar su hipótesis de trabajo. Según refiere, solía iniciar el diálogo preguntando sobre las enfermedades más comunes: “¿De qué sufren acá?” “¿Qué les duele y por qué”? Y en cierta ocasión obtuvo una respuesta significativa: "Bueno, tos, gripe, cólicos. Pero más que enfermedades, lo que nos agarra son los males del campo" (58), los llakis, que Theidon define "como pensamientos o recuerdos penosos que llegan al corazón" (64); no se pueden olvidar, ya que "se sedimentan en nuestros cuerpos" (76) y se trasmiten en un sentido literal, lo cual muestra "hasta qué punto estas categorías del malestar refieren a trastornos de las relaciones sociales, y a la confusión espiritual y moral que caracterizan a una sociedad de posguerra" (58). La percepción de los males como exteriores, que "agarran a la persona" y "entran en ella", borra las diferencias entre "cuerpo" y "alma", "emoción” y "razón”, y se vinculan con la locura. Es el caso de la "teoría elaborada respecto de la trasmisión al bebé del sufrimiento y del susto de la madre, sea esta trasmisión en el útero o por medio de la sangre y de la leche" (77). Más de un testimonio de las campesinas quechuahablantes le permitió a Theidon acuñar el término "teta asustada" para referirse a este mal, al que me referí líneas arriba. ¿Qué experiencias vividas causan este mal, este susto en las madres?

Durante los años del conflicto armado, centenares de mujeres adultas, jóvenes y niñas fueron víctimas de violaciones masivas o individuales; algunas ya estaban embarazadas; otras lo fueron, producto de la violación: "Las madres nos dijeron que no podían amamantar a sus bebés porque les trasmitirían su terror y memorias malignas, y temían estar pudriendo las mentes de sus niños con 'su leche de rabia y preocu- 
pación"”. Para Theidon, no se trata de una "creencia andina", "exótica”, ajena a la racionalidad occidental: muchos científicos comparten la idea "de que uno puede transmitir su dolor, su sufrimiento, su memoria a su bebé por el útero o por la lactancia materna [...]. Diversos estudios han demostrado que si una mujer está con estrés, con trauma, escapando de grupos armados, sin poder comer bien, sin poder respirar y dormir puede transmitir eso a su bebé", sostiene (Largaespada).

\section{La película de Llosa}

Interrogada por Ricardo Pineda sobre el origen del argumento, Llosa, directora del filme La teta asustada, respondió:

La historia es absolutamente ficción. A partir de una serie de investigaciones, sobre el conflicto armado en Perú durante los años ochenta, cayó en mis manos el libro Entre prójimos, de Kimberly Theidon. Es un recopilatorio de testimonios que nada tiene que ver con lo que narra la película, pero sí una enfermedad: la que transmite el miedo y el sufrimiento de madres a hijos a través de la leche materna. Me quedé conectada con la idea y sentí la necesidad de profundizarla. Ese fue el punto de partida (Pineda 2013).

Si para Llosa fue un mero punto de partida, "que nada tiene que ver con lo que narra la película", Theidon fue la primera, y feliz, sorprendida cuando quienes conocían su libro la empezaron a llamar por teléfono, felicitándola por la película ganadora del "Oso de Oro", de la cual era "autora intelectual". Su respuesta fue que ella no había hecho nada; que todo el mérito era de la película y que se sentía muy agradecida de que hablara del mal de la "teta asustada": "Como académica, no imaginas que alguien vaya a leer tu texto. Muchos textos académicos son horribles, nadie quiere leer salvo quienes tenemos que leer" (Largaespada). Theidon cita al antropólogo Marcel Mauss y su teoría sobre "los dones que circulan entre la gente van tejiendo redes, obligaciones, reciprocidades". Para mí, "fue un don, un regalo, una experiencia inolvidable escuchar a esas mujeres", quienes al confiar en ella le encargaron "hacer algo". ¿Qué podía hacer para corresponder, circular esas 
experiencias? Que haya inspirado a una directora de cine, que se haya convertido en un filme que lo verá mucha más gente de la que lee los textos académicos "es más de lo que hubiera soñado". [...] Me gusta todo del filme, la simbología, el tratamiento de los personajes, la canción en quechua que canta la madre moribunda narrando su violación", declaró en la entrevista citada.

Si bien no estamos ante ninguna disputa por autoría intelectual, parto de la premisa de que es insuficiente limitar la relación intertextual -Robert Stam (2000), la llamaría hipertextual, siguiendo a Genette (1989) - ${ }^{2}$ a un "punto de partida", como lo señala Llosa, o a "los temas" a los que se refiere Theidon muy brevemente: "El guion lo elaboró Claudia Llosa y ella introdujo elementos de realismo mágico, pero tomó los temas que no son inventados" (Largaespada). En realidad, ambas declaraciones dan cuenta de la relación explícita entre ambos textos, pero esta ha pasado desapercibida para estudiosos y críticos, tal vez porque la película no hace ninguna referencia a la investigación de Theidon bajo ninguna de las convenciones usuales que en estos casos se estilan en la presentación de los créditos: "Película basada en", "Inspirada en", "Versión libre", "adaptación"; ni tampoco como cita bibliográfica, según las reglas que rigen la citación de fuentes en la investigación académica.

Sea esta u otra la razón, lo cierto es que, aun cuando ni la investigadora ni la directora/guionista del filme niegan la relación entre el uno y otro, poco o nada se ha trabajado en este más que explícito diálogo intertextual y considero que indagar en algunos aspectos de dicha relación, prestando atención a la manera como Llosa ficcionaliza la investigación de Theidon, permitirá aproximaciones al filme no consideradas en los estudios que ignoran o desconocen el trabajo de Theidon.

En Palimpsestes (1989), Genette desarrolla, entre otros conceptos analíticos relacionados con la noción de la "intertextualidad" acuñada por Kristeva y que prefiere llamar "transtextualidad", el de hipertextualidad que remite a la relación entre un texto anterior, "hipotexto" que es transformado, modificado, elaborado o ampliado y da lugar a un nuevo texto, el hipertexto. 


\section{La ficcionalización de la investigación de Theidon: ¿Es posible hablar de adaptación?}

Proponer el siempre discutido término adaptación para referirse a la relación entre la película La teta asustada y Entre prójimos puede parecer inapropiado, por cuanto el hipotexto no es la usual novela adaptada, sino una investigación antropológica con fines académicos. Y más inapropiado aún para quienes entienden que las adaptaciones deben ser "fieles", ya sea al texto original considerando la trama y los personajes o, a lo que algunos críticos, como Pauline Kael (Deeper into Movies), citada por Stam, llaman la "esencia" o "especificidad" de cada medio de expresión que supone que cada medio es "inherently 'good at' certain things and 'bad at' other [...]. Movies are good at action; they're not good at reflective thought or conceptual thinking. They're good at immediate stimulus, but they're not a good means of involving people in the other arts or in learning about a subject. The film techniques themselves seem to stand in the way of the development of curiosity"3 (Kael, cit. en Stam 2000: 58).

Según esta concepción, las películas no pueden ser inteligentes o reflexivas ni tienen capacidad para elaborar y profundizar ideas; son buenas solo para la acción. Stam, cuestiona esta postura acusando a Kael de compartir el elitismo literario que, asume que el cine carece de la dignidad y profundidad propias de la literatura, y desarrolla una sólida argumentación, discutiendo tal esencialismo ontológico en más de un trabajo (Stam 2000, 2009), en los que señala los prejuicios que explican esta concepción a la cual califica de elitista: entre ellos, el de "seniority", asume que las artes antiguas son necesariamente superiores a las modernas; el de "iconophobia" afirma que las artes visuales son necesariamente inferiores a las verbales; y el de "logophilia", que valoriza la palabra desdeñando la imagen (Stam 2000: 58).

inherentemente 'bueno en' ciertas cosas y 'malo en' otras [...]. Las películas son buenas para la acción; no son buenas para el pensamiento reflexivo o el pensamiento conceptual. Son buenas para el estímulo inmediato, pero no son un buen medio para involucrar a las personas en las otras artes o para aprender sobre un tema. Las técnicas de la película parecen obstaculizar el desarrollo de la curiosidad. 
Es evidente que, desde una postura esencialista como la señalada, resulta inadecuado y fuera de lugar, por no decir imposible, analizar la relación entre el libro de Theidon - un estudio académico que desarrolla ideas - , y el filme ficcional de Claudia Llosa, que narra una historia "con imágenes", como se suele definir al cine narrativo. Pero si descartamos los prejuicios y asumimos una teoría más moderna de las adaptaciones, la figura de la "adaptación como lectura" ("adaptation as a Reading”), acuñada por Stam (2000: 62), los resultados serán más productivos en tanto que la interpretación de cada texto está determinada por las lecturas particulares de los diferentes receptores. Lo que hace un director de cine con un texto - novela, cuento, investigaciones periodísticas, antropológicas, estudios de cualquier tipo-, considerado hipotexto, según la clasificación de Genette (1989), al convertirlo en una película (hipertexto), propone su lectura personal de aquel. Desde esta perspectiva, más allá de si gusta o no, transforma el hipotexto mediante una compleja serie de operaciones: "selection, amplificaction, concretization, actualization, critique, extrapolation, analogization, popularization, and reculturalization"4 (Stam 2000: 68). En la sección final de Teoría y práctica de la adaptación, Stam propone que el estudioso de las adaptaciones debe intentar responder a preguntas claves: “¿Qué principio guía los procesos de selección o triage cuando alguien está adaptando una novela? ¿Cuál es el sentido de estos cambios? ¿Qué principios determinan la selección?" (2009: 78). Se trata, en suma, de ir más allá del simple inventario que consigna los cambios en el argumento y personajes, con el único fin de determinar la fidelidad o infidelidad al hipotexto, para prestar atención a los añadidos, omisiones, y/o alteraciones y a cómo estas crean significados distintos entre texto y filme. La búsqueda de respuestas a interrogantes como: ¿qué se elige contar?, ¿qué enfatiza?, ¿qué aspectos desdeña?, ¿cuáles destaca?, etcétera, dará luces sobre la producción de nuevos sentidos y significaciones como resultado del proceso de adaptación.

Bajo el marco conceptual propuesto por Stam, es válido entonces considerar la relación entre el estudio de Theidon y la película de Llosa como una adaptación, en el sentido amplio de "lectura", descartando

selección, amplificación, concretización, actualización, crítica, extrapolación, analogización, popularización y reculturalización. 
la definición convencional de adaptación que solo presta atención a las transposiciones de novelas ficcionales, tal vez biografías y autobiografías, mas no a trabajos teóricos o académicos. En lo que sigue me interesa responder a la pregunta sobre cómo "lee" Claudia Llosa el estudio de Theidon.

El vínculo más evidente es, sin duda, el título, que remite de manera directa a la enfermedad, "bautizada" así en español por Theydon, y que "descubrió" durante las entrevistas a muchas mujeres campesinas, como señalé al inicio. La sinopsis y publicidad de "La teta asustada" enfatizó en esta enfermedad: Fausta (Magaly Solier) padece la teta asustada, una rara enfermedad que se transmite por la leche materna de mujeres que fueron violadas durante la gestación y la lactancia en la época del terrorismo. Un terror atávico que se transmite de generación en generación y que Fausta sufre en forma de hemorragias nasales en momentos de crisis (TrailerPeruano 2011).

En la investigación de Theidon, Salomé Baldeón ${ }^{5}$ relata que su hija nació al día siguiente de la matanza de Llocllapampa. Intentó dejarla en un cerro, para que se muriera "¿Cómo ya iba a vivir así? Yo le había pasado todo mi sufrimiento con mi sangre, con mi teta". Pero no pudo abandonarla: la bebé lloraba, los soldados podían escuchar. En el presente de la entrevista, la niña tiene 17 años y así es como la describe su atribulada madre:

Ya tiene 17 años y está en quinto grado. No puede pasar, todos los años repite. Dice que le duele la cabeza, le quema, qué será, susto. Desde bebita era así. Le he hecho ver con un curandero, y ellos le han cambiado la suerte. Un tiempo está bien y después sigue igual. La he llevado a la posta y me han dado una pastilla (dicloxicilina) para que tome diario. ¿Qué será? Ya no quiere tomar (Theidon 2009: 77).

Ciertamente, la joven no es Fausta, la protagonista de La teta asustada; pero en el testimonio de Salomé, y de otras madres, se prefigura ya la creación de su personaje víctima del mal de la teta asustada. La madre de Fausta, quien al inicio del filme relata su historia mediante un

Theidon cambió los nombres de las personas entrevistadas. 
canto en quechua, al que me referiré enseguida, también se prefigura en las mujeres cuyos testimonios refieren la violencia sexual que padecieron. En el capítulo 8, titulado "A la fuerza", Theidon relata cómo las viudas y las solteras fueron las más vulnerables; cómo intentaron defenderse "con palos, dientes, gritos y puños", o cómo recurrieron a diferentes estrategias para evitar ser violadas: "Llenaron sus faldas con ropa, fingiendo estar embarazadas para disuadir a los soldados, mientras que otras echaron sangre en su ropa interior, esperando que su estado sangrante desanimara a los violadores. Y, notablemente, otras recurrieron a los 'embarazos estratégicos' para ejercer alguna forma de control sobre sus cuerpos" (111).

Asimismo, muchas mujeres narraron que aceptaron ser violadas a cambio de salvar al hijo, al hermano, al esposo; y también refirieron violaciones organizadas "por rango y por turnos, comenzando por los oficiales y terminando con los reclutas" (122). Una de las entrevistadas contó que "Violaban hasta que las señoras no podían pararse" (121). Tras la escucha de estos testimonios, Theidon afirma:

Hemos explorado las teorías que maneja la población rural quechuahablante respecto de la trasmisión de los llakis y del susto de la madre del bebé, ya sea a través del útero o por medio de la 'teta asustada' o de la sangre. Entonces, es lógico que también se manejen teorías sobre el impacto de la violación en las madres gestantes cuyos bebés nacen sin el uso de razón (129).

A la luz de esta información, Llosa construirá una trama ficcional dotada de una sólida estructura que si bien se independiza del estudio antropológico, no reduce este a mero punto de partida: el sufrimiento de la madre de Fausta y la enfermedad del susto que le trasmite a su hija están contenidos en los testimonios, así como otros aspectos que desarrollaré más adelante.

Veamos la función y significaciones de la papa que Fausta se coloca en la vagina para no ser violada como su madre. Se trata, evidentemente, de una estrategia análoga o equivalente a aquellas realmente empleadas, de acuerdo con los testimonios recogidos por Theidon. Pero es inverosímil, de manera que el espectador tiene que atribuirle un valor metafórico que trasciende el testimonio y añade un significado nuevo, 
lo cual constituye un importante aporte del filme en el plano simbólico, considerando, además, las connotaciones culturales que tiene la papa en el mundo andino. “¿Realmente hay mujeres con papas en sus vaginas?”, comenta Theidon que era una de las preguntas más frecuentes que le hacían los periodistas. Y su respuesta es firme, sin asomo de duda alguna: "No, hay mucha papa en el campo pero no en las vaginas, pero sí hubo muchas estrategias para evitar la violencia sexual" (Largaespada). El crítico Emilio Bustamante entiende que: "Con la papa, Fausta pretende impedir la violación, pero en realidad la mantiene presente. Cuando la papa empieza a germinar en su cuerpo, ella corta los brotes como si cortara las uñas o los pelos de un cadáver. La papa es un cadáver; Fausta conserva a la muerte dentro de sí. Sigue vinculada al pasado doloroso que le impide integrarse al mundo emergente que la rodea" (2009).

La papa en la vagina de Fausta deviene en el punto central de la ficción creada por Llosa. Funciona como una metáfora inquietante que aun cuando desestabiliza el verosímil realista, conducirá la línea narrativa y el conflicto dramático desde el inicio, cuando el médico del hospital donde han acudido - porque Fausta ha sufrido un desmayo y le sangra la nariz - le revela al tío que su sobrina tiene "un tubérculo en la vagina, una papa para ser más exactos" y que debe ser extraída pues se está propagando y causará serias infecciones. El tío explica que Fausta sangra por la enfermedad, por la teta asustada. "Así nació, nada de papa, doctor. Ella sufre de la teta asustada”. Y pregunta: “¿Esa enfermedad no hay acá en Lima, no, doctor?" El médico afirma con absoluta certeza que esa enfermedad no existe en ninguna parte. En el ómnibus, Fausta le dice al tío que no va a permitir que le saquen la papa. Su mamá le contó que en el tiempo del terrorismo una vecina lo hizo para que no la violaran ni unos ni otros. Después ya se casó y tuvo cuatro hijos. El tío no quiere hablar del pueblo ni del terrorismo ni del pasado: "Ahora es otro tiempo. Acá en Lima todo es diferente. Nadie te va a hacer nada. Tu mamá está muerta, muerta está". En adelante, asistiremos al proceso de curación de Fausta; para que ello ocurra, deberá enterrar a la madre y extraerse la papa de la vagina.

Víctima del mal de la teta asustada, Fausta está llena de llakis, pensamientos, recuerdos trasmitidos por su madre: "Los llakis pueden llenar el cuerpo y robarle a la persona su uso de razón, dejándola sonsa, sin 
sentido... y conforme van madurando [...] pueden llegar a ser fatales" (66), explica Theidon luego de escuchar las informaciones de varios curanderos. La ficcionalización de Llosa elabora este concepto a partir de la construcción de Fausta padeciendo hemorragias y desmayos constantes, cargando a cuestas el miedo heredado en su imposibilidad de caminar sola y en la infranqueable distancia que la separa de los demás excepto de su madre, el único cuerpo con el que puede compartir alguna intimidad.

En este sentido, una nota a pie de página en el acápite titulado "Hacer querer" ilumina la lectura de Llosa. En esta nota, Theidon señala que en las comunidades donde realizó su investigación, fue común encontrar la noción de "Hacer querer" como parte del proceso de construcción del ser humano y que significa el aprendizaje del amor en el sentido en que cada uno tiene que saber "hacer querer" a otros; y hacerse querer por los demás. Sin embargo, según muchos testimonios, varias madres dijeron "que la violencia política había dañado a sus niños, quienes nacieron sin poder querer. Esto implica que nacieron sin una facultad humana central: uno no podría fomentar el amor en esos niños dañados" (62). Es evidente que la Fausta de la película está dañada, no sabe hacer que la quieran; no sabe querer más que a su madre; y Llosa lo narra a lo largo del filme, colocándola siempre en los márgenes, apartada de la fiesta, encerrada en sí misma, siempre sola en una habitación extraña; sola en su habitación junto a su madre muerta; sola y sentada al borde de la cama, o de pie en un rincón de la cocina de la casa de la señora donde ha ido a trabajar y con quien prácticamente no cruza una palabra. Asimismo, el intento del joven amigo de la familia por acompañarla y salir con ella recibe como respuesta un "no" rotundo. Y cuando tiene que participar de la vida familiar con los tíos, primos y vecinos, o en las fiestas de matrimonio, permanece ajena y distante. Recuérdese la escena de la piscina: el tío cava la fosa para enterrar allí a la madre de Fausta, pero como ella quiere llevarla al pueblo, lo que sería tumba se convierte en piscina para el goce de la familia, niños y adultos, que pasan momentos divertidos y felices bañándose mientras Fausta permanece en la habitación, velando a su madre muerta.

La madre de Fausta es un personaje fundamental. Conocemos su historia, que recuerda los testimonios presentados por Theidon, en la primera escena narrada a través del canto: "la agarraron, la violaron 
con su pene y con su mano y la hicieron tragar el pene muerto de su marido muerto" [...] "A ti te ha parido una perra con rabia". Este canto remite, aunque en un contexto y una temática diferentes, al quarami, forma narrativa de larga data en la sierra peruana "y se refiere a poemas ceremoniales o baladas" (Theidon 132). De acuerdo con la experiencia de la investigadora, en los tiempos actuales solo lo cantan las viudas de la zona norte (en el centro sur ayacuchano está desapareciendo) en los eventos importantes: matrimonios, inauguración de carreteras, visitas importantes y "se inclina hacia lo burlesco", lo que permite a las mujeres "tanto conmemorar los eventos como opinar sobre ellos" (133). El quarami que canta la madre de Fausta se acerca más al referido por José Uriel García (1925), quien lo define como "toda escala sentimental que canta las intimidades del alma, de la pasión amorosa, el llorar por los muertos". Citada esta definición en Theidon (133), el canto agónico de la madre de Fausta narrando su sufrimiento en los tiempos de la violencia, bien puede haber sido creado por Llosa a partir de esta información que brinda el texto. Apoyándome en la definición de Uriel García, es posible afirmar que cuando Fausta se encuentra sola, los quarami le permiten expresar sus penas y sus miedos. Es importante observar que el canto de Fausta se convierte en el eje estructurador del filme de Llosa, no solo porque determina la trama o anécdota, pues de estos cantos se apropiará la mujer en cuya casa Fausta trabaja como empleada de servicio, sino por su valor expresivo y comunicativo. El canto como trasmisor de emociones y medio de comunicación forma parte sustancial de la cultura andina.

Otro aspecto que desarrolla ampliamente la investigación de Theidon es el del "pluralismo médico", que remite a la existencia de "sistemas paralelos de salud y enfermedad que operan en cualquier sociedad" (89). En los pueblos rurales se maneja muy bien la diferencia "entre las enfermedades que se tratan en la posta y los males que se llevan al curandero" (89). Esta información, que muestra una clara diferenciación entre dos tipos de males o padecimientos, en el filme de Llosa se traslada a una de las primeras secuencias, en la que se destaca la incongruencia o incompatibilidad entre la medicina occidental y las "creencias" mágicas o ancestrales, percibidas como obstáculos que impiden el avance a la modernidad. Esta oposición es narrada con claridad 
y contundencia en las escenas en las que el médico, representante del racionalismo occidental, ignora el mal de Fausta y lo atribuye, menospreciándolas, a creencias que son producto de la ignorancia y del pensamiento mágico de los campesinos. Por el contrario, si bien Theidon pone menos énfasis en la incompatibilidad, sugiere una suerte de asignación de roles claramente definidos:

campesinos y campesinas van a la posta para obtener sus bolsas de papilla, sus ampollas anticonceptivas y pastillas para la tos, la gripe y los cólicos [...] y con los curanderos tratan lo que está mal en el mundo: los ancestros que están enojados, el vecino envidioso, los llakis que atormentan el cuerpo y el alma. Los ex enemigos cuya presencia en el pueblo irrita el corazón y la tierra misma que los agarra cuando pisan descuidadamente donde no se debe pisar (90).

Llosa opta, al no plantear la diferencia entre los males que atiende el curandero y los que se curan en la posta médica, por la solución "urbana", en tanto que propone un desenlace en el que el médico "cura" a Fausta extrayéndole la papa de la vagina. Y es la misma Fausta quien pide que le saquen la papa, una vez que ya ha conseguido el dinero para llevar al pueblo el cadáver de su madre. La metáfora funciona: Fausta ha logrado establecer un vínculo con el jardinero; y no es casual que sea él quien la lleve al hospital donde se curará. Y una vez extraída la papa, enterrará a su madre; es decir, logrará quitarse la muerte que llevaba dentro, los llakis que no la dejaban vivir, los que le trasmitió su madre con la leche. Así, se inserta en la vida urbana y puede iniciar su integración a la ciudad.

Como en el estudio de Theidon, en el filme aparece también la figura, reelaborada, de los pishtacos. Concebidos desde la mitología como seres sobrenaturales que matan a la gente para extraer su grasa y venderla en los mercados internacionales, son una metáfora de la explotación de los foráneos que impusieron la desigualdad, el abuso y las diferencias jerárquicas. En muchas de las entrevistas realizadas, refiere Theidon, el pishtaco puede ser el senderista o el soldado o el extranjero, pero siempre es representado como un ser humano blanco, de elevada estatura y ojos verdes. Es la figura del que explota y abusa, del que roba y destruye. Llosa, leyendo inteligentemente a Theidon, construye una "pishtaca" en la señora de la casa alta donde va a trabajar Fausta. Y como 
"pishtaca", la señora limeña le roba su talento a la joven: a cambio de canciones, la señora le dará perlas que se irán acumulando en una balanza, hasta el momento en que ya no necesite sus servicios. Así, Fausta podrá venderlas y pagar el entierro de su madre. Se trata de una representación sugerente que trasciende el viejo realismo indigenista que mostraba un Perú esquemáticamente dividido en dos mundos: el de los blancos explotadores y el de los indígenas explotados y victimizados, por cuanto, en La teta asustada, la figura de la mujer alta, blanca y de ojos verdes deviene en símbolo; encarna la metáfora de la explotación ancestral de la cual han sido víctimas las comunidades andinas. Si la novela realista peruana denunció la explotación dando cuenta del robo de tierras, la explotación minera, el sistema de servidumbre, entre una larga lista de abusos, Llosa construye la trama del robo o plagio de la voz, representada por la expresión musical que se constituye como la última posesión de quien lo ha perdido todo.

Puede pensarse que la gran diferencia entre el texto de Theidon y el filme de Llosa radica en la ficcionalización que instala al personaje en un asentamiento humano de la ciudad de Lima, en tanto que Theidon transita entre las comunidades rurales de Ayacucho. Sin embargo, la distancia entre el estudio antropológico y la película trasciende la anécdota, la trama, e incluso la línea dramática pues refiere al sentido, a la significación de la propuesta. El trabajo de Theidon, como lo señalé al principio, parte de la premisa de que "la patología se halla en las formas estructurales y políticas de la violencia" y que, explorando las enfermedades y sus causas podemos entender "cómo la salud y el malestar son producidos social e históricamente" (49). Se trata de una perspectiva que denuncia la continuidad de la violencia estructural en la sociedad posconflicto, las "violencias" que menciona refiriéndose al "hambre crónica y la pobreza" (48), la discriminación étnica y el racismo (57). En suma, la curación solo es posible si se presta atención a "los vínculos estrechos entre la psicología social, la pobreza y las relaciones sociales tensas en muchos de estos pueblos" (58). Aunque Llosa también elabora la continuación de la violencia estructural a través de la relación de dominio y discriminación a Fausta por parte de su patrona, ${ }^{6}$ la trama de La teta asus-

Recordemos que la patrona nunca llama a Fausta por su nombre ni le dirige la palabra, es decir, la "ve" solo cuando necesita un servicio doméstico o le resulta útil 
tada, "psicopatologiza", individualizándola, la enfermedad de Fausta. $\mathrm{Al}$ instalarla en el asentamiento humano donde el tío y su familia están construyendo con entusiasmo y entrega una nueva vida inmersos en la adquisición de una cultura "costeña", convencidos de que el pasado quedó atrás, se aleja totalmente de la premisa y propuesta de Theidon. Fausta y su madre son las únicas enfermas en ese grupo emergente de gente alegre y confiada en el futuro. Y están muertas o enfermas porque se quedaron en la sierra. El mensaje es optimista: si bien la madre muere a causa de los llaquis, de los males del campo que "la agarraron" y no la soltaron, Fausta sí podrá curarse gracias al médico del hospital, al jardinero y a la Lima del asentamiento humano donde solo basta tener la voluntad de integrarse y trabajar en el negocio familiar. Todos están invitados a participar y colaboran en la medida de sus posibilidades, mientras ofrecen y reciben regalos, se enamoran, bailan en las bodas, se fotografían y viven, en fin, confían en el progreso y el éxito. El racismo, el abuso, la explotación y todas las "violencias", pertenecen al pasado; o quedaron en la casa de la "pishtaca", confinada en un mundo que agoniza por su propia decadencia. Así, Lima y el asentamiento humano devienen en una suerte de paraíso en relación con la sierra que dejaron atrás. No en vano para llegar es preciso subir innumerables escaleras, esas que, según la canción popular, se necesitan "para subir al cielo".

Dos conclusiones básicas. La primera: al ser la película un hipertexto ficcional que parte de un hipotexto académico, no ficcional, se inscribe en el ámbito de la ficción, el texto literario se "adapta" y deviene en película. En suma, La teta asustada de Llosa muestra que es posible plantear otros tipos de relaciones, acercamientos y distancias mediante lecturas que otorgan nuevos sentidos, tanto al texto de origen, hipotexto, como al resultado de la "adaptación", el hipertexto. La segunda: la indagación en algunos aspectos planteados en el diálogo intertextual entre la investigación de Theidon y el filme de Llosa ha permitido ob-

para "inspirar" su creación musical, aporte que finalmente no reconocerá. Desde su perspectiva discriminatoria, no le debe nada a Fausta. Asimismo es bastante significativa como muestra de la violencia discriminatoria la escena en la cual Fausta es instruida por la empleada principal de la casa quien le trasmite el pensamiento de la patrona y la entrena para que cumpla a cabalidad su papel de subalterna: atender la llamada, mantenerse limpia, usar desodorante porque la patrona no tolera el mal olor, etcétera. 
servar los diferentes modos de ficcionalización elaborados en el filme y observar cómo estos reelaboran, replantean, amplifican o desarrollan los resultados de la investigación desde la peculiar mirada de la cineasta. Podemos afirmar que ambos textos se iluminan y enriquecen mutuamente en este diálogo intertextual de ida y vuelta, ante los ojos de nosotros, lectores y espectadores.

\section{Bibliografia}

Bustamante, Emilio (2009). "La teta asustada", en Página del diario de Satán, blogspot, <http://paginasdeldiariodesatan.blogspot.pe/2009/02/lateta-asustada-por-emilio-bustamante.html $>$, consultado por última vez el 10 de noviembre de 2017.

Comisión de la Verdad y la Reconciliación. Informe final <www.cverdad.org. pe>, consultado por última vez el 9 de octubre de 2017.

García, José Uriel (1925). Guía histórico-turística del Cuzco. Homenaje al Centenario de Ayacucho. Lima: Garcilaso.

Genette, Gerard (1989). Palimpsestos: la literatura en segundo grado. Madrid: Taurus.

LARGAESPADA, Mildred (s.f.). "La teta asustada: la historia detrás de la película", <http://periodismohumano.com/culturas/la-teta-asustada-la-historia-detras-de-la-pelicula.html>, consultado por última vez el 9 de octubre de 2017. LlosA, Claudia (directora) (2009). La teta asustada. Protagonistas: Magaly Solier, Marino Ballón, Susi Sánchez. España / Perú: Wanda Visión.

PINEDA, Ricardo (2013). "Entrevista a Claudia Llosa: 'No pretendo interpretar la realidad",, <https://ideasdebabel.wordpress.com/2013/02/08/entrevistaa-claudia-llosa-no-pretendo-interpretar-la-realidad-por-ricardo-pineda/>, consultado por última vez el 15 de diciembre de 2017.

Stam, Robert (2000). "Beyond Fidelity: The Dialogics of Adaptation", en Film Adaptation. James Naremore. New Bruswick, Rutgers University Press.

STAM, Robert (2009). Teoría y práctica de la adaptación. México: Universidad Nacional Autónoma de México <en línea>.

THEIDON, Kimberly (2009). Entre prójimos. El conflicto armado interno y la política de reconciliación en el Perú. Lima: Instituto de Estudios Peruanos.

TrailerPeruano, "La Teta Asustada (2009) Trailer", Youtube, 4 de enero de 2011, <https://www.youtube.com/watch?v=mDUCnvcacxc>, consultado por última vez el 9 de octubre de 2017. 